\title{
Priapism as the Presenting Complaint in Fatal Group A Streptococcal Induced Disseminated Intravascular Coagulation
}

\author{
Richard J. Baverstock, MD*; Colleen Carey, $\mathrm{MD}^{\dagger}$ \\ ABSTRACT
}

A 60-year-old male presented to an emergency department (ED) with priapism following a sore throat illness. He did not have typical findings of sepsis. The patient then developed severe headache, mental status changes, and hypertension, then suffered a cardiopulmonary arrest. Autopsy showed group A streptococcal (GAS) sepsis, disseminated intravascular coagulation (DIC), and a septic thrombosis to the penile vein. This is the first known case of priapism being the presenting symptom of DIC.

\section{RÉSUMÉ}

Un homme de 60 ans a consulté au service des urgences pour du priapisme consécutif à un mal de gorge. Le malade ne présentait pas de signes classiques de la sepsie, mais son état s'est détérioré par la suite : céphalée intense, altération de l'état mental, hypertension, puis arrêt cardiorespiratoire. L'examen a révélé à l'autopsie une sepsie à streptocoques du groupe A, une coagulation intravasculaire disséminée (CIVD) et une thrombose septique de la veine pénienne. Il s'agit là du premier cas connu de priapisme dans lequel le trouble constituait le symptôme principal d'une CIVD.

Keywords: priapism, DIC, Group A Streptococcus

\section{CASE}

A 60-year-old man presented to the ED at 3:30 am complaining of pain and swelling to his penis which had onset at 6:30 pm the preceding evening. He had three days of sore throat, fatigue, and general malaise with possible fever and had been taking a cold and sinus remedy (ibuprofen/pseudoephedrine). His medications included pravastatin and perindopril. He denied use of any phosphodiesterase inhibitors or other treatments for erectile dysfunction. He denied tobacco, alcohol, street drug use, and herbal remedies.

Initial vital signs were: $36.4 \mathrm{C}^{\circ}, \mathrm{HR} 72, \mathrm{RR} 23, \mathrm{BP}$ $135 / 76$ and $98 \%$ on RA. He appeared severely distressed and was moaning in pain due to a penis that was erect, firm, and markedly tender with no skin changes. Full physical examination revealed a normal oropharynx, and non-tender, reducible left inguinal hernia, and nothing else contributory. Laboratory values: $\mathrm{Hb}$ of $133 \mathrm{~g} / \mathrm{L}$, WBC $11.6 \times 10^{9} / \mathrm{L}$ with a neutrophilia of $11.2 \times 10^{9} / \mathrm{L}$ (2.0-8.0), and platelets $187 \times 10^{9} / \mathrm{L}(150-400)$. Sodium was $129 \mathrm{mmol} / \mathrm{L}(133-145)$, potassium $4.4 \mathrm{mmol} / \mathrm{L}(3.3-5.1)$, chloride $93 \mathrm{mmol} / \mathrm{L}(98-111), \mathrm{CO}_{2} 19 \mathrm{mmol} / \mathrm{L}$ (21-31), and creatinine $90 \mathrm{umol} / \mathrm{L}$ (50-120).

A diagnosis of ischemic priapism was reached. The preceding sore throat was judged to be irrelevant. A decision to aspirate blood from the corpora cavernosum and inject phenylephrine was made. The patient received sedation by propofol and fentanyl with hemodynamic monitoring. As per European Association of Urology Guidelines ${ }^{1}$, a total of $1,500 \mathrm{mcg}$ of phenylephrine was delivered with aspiration via an 18-G butterfly needle to the right and left corporal bodies during two separate sessions spaced one hour apart. The priapism did not resolve, so the urology service was consulted at 7:30 am. A large hematoma at the injection site on the penile shaft was noted.

Urology noted severe penile pain. The penis was bruised and swollen with a blackened glans, raising the concern for tissue necrosis secondary to phenylephrine. A Marcaine penile block temporarily relieved the pain. Given the lack of a clear etiology, discussion with Interventional Radiology was initiated to consider the role of an angiogram for further diagnosis and treatment. A corporal shunt was also considered.

At $11 \mathrm{am}$ the patient ambulated to the bathroom. He strained to urinate then developed a severe headache. He walked back to his bed where he became diaphoretic,

From the *Department of Surgery and tDepartment of Emergency Medicine, University of Calgary, Calgary, AB.

Correspondence to: Dr. Richard Baverstock, 6601, 7007 14th St SW, Calgary, AB T2V 1P9; Email: richard.baverstock@ahs.ca 
hypoxic, and nauseated. A portable chest $\mathrm{x}$-ray showed no active cardiopulmonary disease. At $12 \mathrm{pm}$, his blood pressure increased to $218 / 131 \mathrm{~mm} \mathrm{Hg}$, the patient became agitated then unresponsive and apneic. Artificial respirations were initiated immediately and the patient intubated. He then suffered a cardiac arrest and attempted advanced cardiovascular life support (ACLS) resuscitation was unsuccessful.

Autopsy revealed GAS in the blood and lung tissue. Unresolved priapism was noted with septic penile vein thrombosis and infarction. There were septic thromboses (clots containing GAS bacterium) in the blood vessels of the brain, kidneys, heart and lungs, and accelerated post-mortem decomposition.

\section{DISCUSSION}

Following the autopsy findings, the presumed pathophysiology is that streptococcal pharyngitis led to invasive GAS (iGAS) disease causing disseminated intravascular coagulation (DIC). Priapism was the predominant presenting feature of DIC. The patient did not clinically appear to have sepsis and remained hemodynamically stable until approximately one hour before his death. He did not manifest the typical ecchymoses, abnormal bleeding, lab work abnormalities, or clinical evidence of other end organ infarction expected in DIC. The absence of typical signs or symptoms of sepsis or DIC in this case is highly unusual, as was the normal platelet count. Coagulation studies and DIC lab work were not ordered because DIC was not suspected clinically. DIC was confirmed by autopsy findings of thromboses in blood vessels of multiple tissues; this is the gold standard for diagnosing DIC. Clinicians are reminded that all DIC laboratory studies have imperfect diagnostic performance. ${ }^{2}$

The possibility that a delayed release of phenylephrine from the penile tissue into the systemic circulation led to the patient's decompensation, with the onset of headache and hypertension, was considered prior to the autopsy results. One case report of phenylephrine treatment of priapism leading to subarachnoid hemorrhage was found; however, the headache and blood pressure increase in that case was immediate following the phenylephrine injection ${ }^{3}$. In our case, the symptoms and blood pressure did not change for four hours after the final phenylephrine injection. Further, the finding of DIC and GAS sepsis on autopsy make the cause of death abundantly clear.
We doubt that phenylephrine contributed in any significant way to our patient's death.

This is the first reported case of ischemic priapism as the predominant finding of DIC. DIC has been caused by iGAS previously as in a case report from the Lancet in 1988 which reported DIC from GAS that led to two maternal and fetal deaths. ${ }^{4}$ Another report described group A strep cervicitis causing DIC in a female patient. ${ }^{5}$ DIC causing priapism is rare but known. In the two prior case reports, we found priapism was part of a constellation of findings of DIC. A 72-year-old male with fever, cough, bronchitis, cirrhosis, and purpura developed priapism after a week of illness which was treated with penile amputation for necrosis. ${ }^{6}$ A 61-year-old male developed priapism secondary to cryptococcal infection contracted from pigeon droppings. ${ }^{7}$ This case of GAS-induced DIC presenting as priapism has never been reported.

The definition of iGAS includes streptococcal toxic shock syndrome (STSS), soft tissue necrosis (e.g., necrotizing fasciitis), meningitis, GAS pneumonia, bacteremia, and other life threatening conditions. ${ }^{8}$ This case would fit within the definition of iGAS. The Alberta Health Notifiable Diseases Guidelines on iGAS, last published in June of $2013,{ }^{8}$ list the incidence of severe iGAS as 6.3 cases per 100,000 persons in 2012. An increase in cases during the 1980s and 1990s was related to an increase in prevalence of the $M 1$ and $M 3$ serotypes. ${ }^{9}$ iGAS occurs more commonly at the extremes of age and in immunocompromised states. ${ }^{8}$ The World Health Organization concludes that 1.78 million new cases of serious GAS occur and are responsible for over 500,000 deaths worldwide annually. ${ }^{10}$

Public attention peaks at times of clusters of iGAS disease. The insidious nature of severe cases in healthy hosts can be alarming. Fox stressed the "necessity of early recognition of the varied presentations of these infections" and stated that invasive GAS is "uncommon but fulminant and often lethal." ${ }^{11}$ General principles of management of iGAS include early antibiotics, source control, and supportive care. Antibiotics should include a beta-lactam to inhibit bacterial reproduction and clindamycin to inhibit exotoxin synthesis. ${ }^{11}$ Surgical debridement of any necrotising soft tissue infections is imperative. Pain out of proportion with physical findings is a red flag for necrotising infection. It is unclear in our case the mechanism for the severe pain experienced by our patient-it may have been the severe ischemia from the priapism itself, or septic emboli 


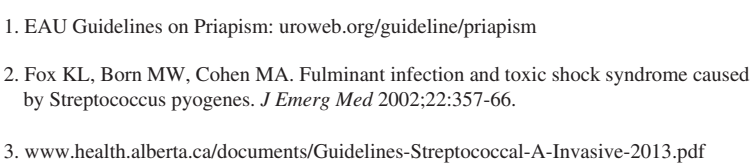

Figure 1. Useful Resources.

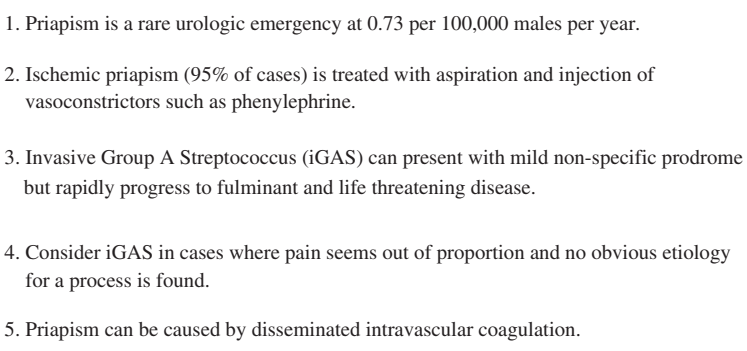

Figure 2. Take Home Messages.

occluding small penile vessels. Necrotizing fasciitis was not found at autopsy.

Priapism, an erection that persists beyond sexual stimulation or is unrelated to it, is a rare urologic emergency estimated at 0.73 per 100,000 male subjects per year. ${ }^{12}$ Three types of priapism have been categorized: ischemic, nonischemic, and stuttering. Etiologies are well described in the recent European Association of Urology (EAU) Guideline. ${ }^{13}$ In practice, ischemic priapism, also known as low flow priapism, accounts for nearly $95 \%$ of all cases. ${ }^{1}$ While the EAU guidelines list idiopathic priapism as the most common etiology ${ }^{1}$, our local experience is that iatrogenic causes-especially injection therapy for the treatment of erectile dysfunction and oral trazodonepredominate. EAU guidelines list many other potential causes for ischemic priapism, however, GAS and DIC are absent from this list.

In conclusion, ischemic priapism is a rare urologic emergency. Usual etiologies include injection therapy for erectile dysfunction, oral medications, and idiopathic. Management pathways can be reviewed on online resources such as the EAU guidelines listed in Useful Resources (Figure 1). When confronted with a case where no etiology is apparent, a search for reversible triggers should be undertaken. This is the first report of a case of GAS-induced DIC causing priapism. The reader is reminded that occult DIC should be considered in patients with their first episode of idiopathic priapism and a poor response to cavernosal aspiration and vasoconstrictor injection. A full history of preceding illness, careful physical examination, and DIC lab work should be considered when clinically warranted. Autopsy can be critical to understanding cases of unexpected mortality. Figure 2 summarizes the key findings of this case.

Competing Interests: None declared.

\section{REFERENCES}

1. Salonia A, Eardley I, Giuliano F, et al. European Association of Urology Guidelines on priapism. Eur Urol 2014;65:480-9.

2. Yu M, Nardella A, Pechet L. Screening tests of disseminated intravascular coagulation: Guidelines for rapid and specific laboratory diagnosis. Crit Care Med 2000;28 (6):1777-80.

3. Davilla HH, Parker J, Webster JC, et al. Subarrachnoid hemorrhage as a complication of phenylephrine injection for the treatment of ischemic priapism in a sickle cell disease patient. 7 Sexual Med 2008;5(4):1025-8.

4. Acharya U, Lamont CA, Copper K. Group A betahaemolytic streptococcus causing disseminated intravascular coagulation and maternal death. Lancet 1988; 1(8585):595.

5. Paraskevaides E, Wilson M. Fatal disseminated intravascaular coagulation secondary to streptococcal cervicitis. Euro 7 Obstet Gynecol Reprod Biol 1988;29(1):39-40.

6. Takamura S, Suzuki Y, Hiei T, et al. A case of priapism caused by disseminated intravascular coagulopathy (Japanese). Acta Urologica Faponica 1987;33(3):453-7.

7. Wagenhauser M, Ertas N, Sagban TA, et al. A 61-year-old man with disseminated intravascular coagulation: a case report. Ann Vasc Surg 2014;28(6):1566 e17-22.

8. Streptococcal disease - Group A, Invasive: Alberta Health Public Health Notifiable Disease Management Guidelines; 2013. Available at www.health.alberta.ca/documents/Guide lines-Streptococcal-A-Invasive-2013.pdf (accessed June 30, 2016).

9. Group A streptococcal (GAS) disease for clinicians: Centers for Disease Control and Prevention (CDC); 2014. Available at www.cdc.gov/groupAstrep/clinicians.html (accessed June 30, 2016).

10. The current evidence for the burden of group A streptococcal disease: World Health Organization (WHO); 2005: Available at www.who.int/maternal_child_adolescent/ documents/fch_cah_05_07/en/index.html (accessed June 30, 2016).

11. Fox KL, Born MW, Cohen MA. Fulminant infection and toxic shock syndrome caused by Streptococcus pyogenes. 7 Emerg Med 2002;22(4):357-66.

12. Roghmann F, Becker A, Sammon J, et al. Incidence of priapism at emergency departments in the United States. 7 Urol 2013;190(4):1275-80.

13. Levey HR, Segal RL, Bivalacqua TJ. Management of priapism: an update for clinicians. Ther Adv Urol 2014; 6(6):230-44. 